Andrea Kocianova - Eva Pitlova*

\title{
CRITICAL GAPS AT UNSIGNALIZED INTERSECTIONS WITH BENDING RIGHT-0F-WAY
}

The capacity calculation procedure for unsignalized intersections is based on the gap-acceptance theory in most of existing capacity regulations and it relies on one of the important parameters - critical gap. However, the capacity calculation procedure and values of critical gaps according to these regulations are valid only for intersections with standard right-of-way (major street leading straight). Nevertheless, in Slovakia, intersections with bending right-of-way (major street not leading straight, but bending) can be encountered. The specific mode of right-of-way results in different priority ranks of traffic movements (set by traffic rules of driving), more complicated traffic situation and therefore, different driver behaviour characteristics. To examine the gap acceptance behaviour of drivers under these specific conditions, an unsignalized four-leg intersection with bending right-of-way located in an urban area of Zilina, Slovakia, was selected. Three different methods (Raff, Wu, and MLM Troutbeck) were used for critical gap estimation from the field data. In the article, results of critical gaps for three through movements of different priority rank (major-street through movement of Rank 2 and minor-street through movements of Rank 3 and 4) are presented. The results show, that the values of critical gaps differ depending on the method by about 3-5\% only, which is not significant. Troutbeck's MLM method gives the highest values. The priority rank of movement has the greatest impact on the result. The values of critical gap for major-street through movement of Rank 2 are the smallest; they are approximately 1.3-2.1 s smaller than the values for minor-street through movements of Rank 3 or 4. The highest values of critical gap have been estimated for minor-street through movement of Rank 4 and they are higher compared to the current Slovak regulations TP 102 values for the same priority rank.

Keywords: critical gap, gap-acceptance behaviour, capacity, unsignalized intersection

\section{Introduction}

Unsignalized intersections are the most widely used type of intersections in the road network. The major street is usually the intersecting street with the dominant traffic volume. For this type of unsignalized intersections, capacity calculation procedure based on the gap-acceptance theory and gap-acceptance characteristics of driver behaviour are determined in most of the existing regulations. However, in Slovakia, intersections with bending right-of-way (major street not leading straight, but bending) can be encountered. The specific mode of right-of-way results in different priority ranks of traffic movements (set by traffic rules of driving), more complicated traffic situation, and therefore, different driver behaviour characteristics. The issue is that for this kind of intersection there is no generally known procedure for capacity calculation and no values of critical gaps determined. For this reason, a four-leg unsignalized intersection with bending right-of-way was chosen and gap-acceptance behaviour of drivers characterized by critical gap times was investigated. In the article, critical gaps for the same traffic movements of different priority ranks estimated by three methods (Raff, Wu and MLM Troutbeck) are presented and compared to values of critical gaps in Slovakia valid for standard intersection with straight major street, according to the Slovak regulations TP 102 [1].

\section{Description of intersection and data collection}

For investigation purposes of the gap-acceptance behaviour of drivers on a specific unsignalized intersection with bending right-of-way, the four-leg intersection located in an urban area of Zilina, Slovakia, was chosen (see Figure 1). Due to the higher load at neighbouring entrances, major street is led in a turn and that causes different redistribution of traffic stream ranks in comparison to traffic management at standard intersection with straight major street. Each traffic stream rank, with its duty to give priority in a specific situation, is shown in Figure 1 and Table 1. However, in practice, for drivers, it is sometimes hard to realize immediately to whom they have to give way [2].

To collect data about traffic load at the investigated intersection, 12-hour traffic survey during a typical working day was performed. The directional distribution and composition of traffic flows were monitored at all the intersection entries. The hourly traffic volumes, with highlighted peak hours in the morning and afternoon, are shown in Figure 2. Traffic patterns during those peak hours, shown in Figure 3, point to a different traffic load redistribution in the morning and in the afternoon. Therefore, the other two 120-minute video recordings during the morning and afternoon peak hours were carried out to collect all the necessary data for critical gap estimation. The total traffic volume on the major street varied from 700 to $1200 \mathrm{veh} / \mathrm{h}$ and 250 to $500 \mathrm{veh} / \mathrm{h}$ on the minor street in this observation time. In addition, the waiting time of minor-stream vehicles, queue lengths, and other factors influencing the critical gaps or follow-up

\footnotetext{
* Andrea Kocianova, Eva Pitlova

Department of Highway Engineering, Faculty of Civil Engineering, University of Zilina, Slovakia

E-mail: andrea.kocianova@fstav.uniza.sk
} 

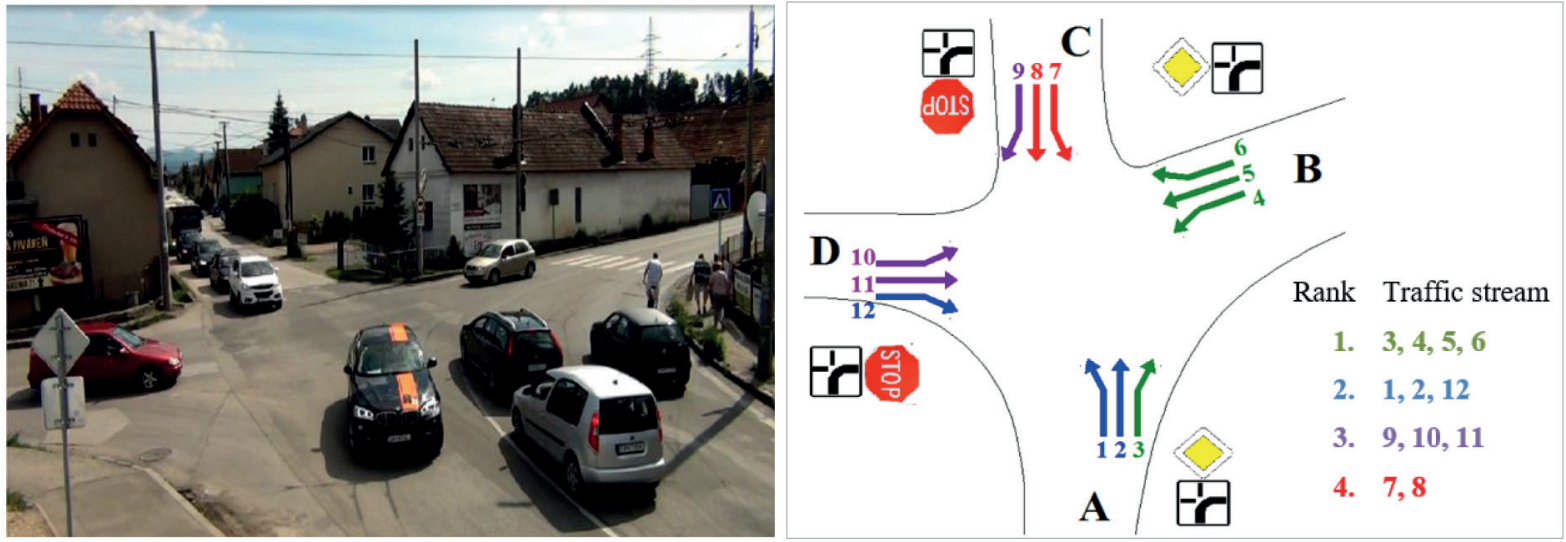

Figure 1 Intersection with bending right-of-way in Zilina and priority ranks of traffic streams at a four-leg intersection

Table 1 Priority rules for traffic streams at the intersection with bending right-of-way

\begin{tabular}{|c|c|c|c|}
\hline Rank of priority & Traffic stream & Movement & Gives priority to \\
\hline \multirow{3}{*}{2.} & 1 & Major-street left-turn & 4,5 \\
\hline & 2 & Major-street through & $4,5,6$ \\
\hline & 12 & Minor-street right-turn & 4 \\
\hline \multirow{3}{*}{3.} & 9 & Minor-street right-turn & 1,5 \\
\hline & 10 & Minor-street left-turn & $1,2,5,6$ \\
\hline & 11 & Minor-street through & $1,2,3,4$ \\
\hline \multirow{2}{*}{4.} & 7 & Minor-street left-turn & $2,3,4,5,10,11$ \\
\hline & 8 & Minor-street through & $1,4,5,10,11,12$ \\
\hline
\end{tabular}

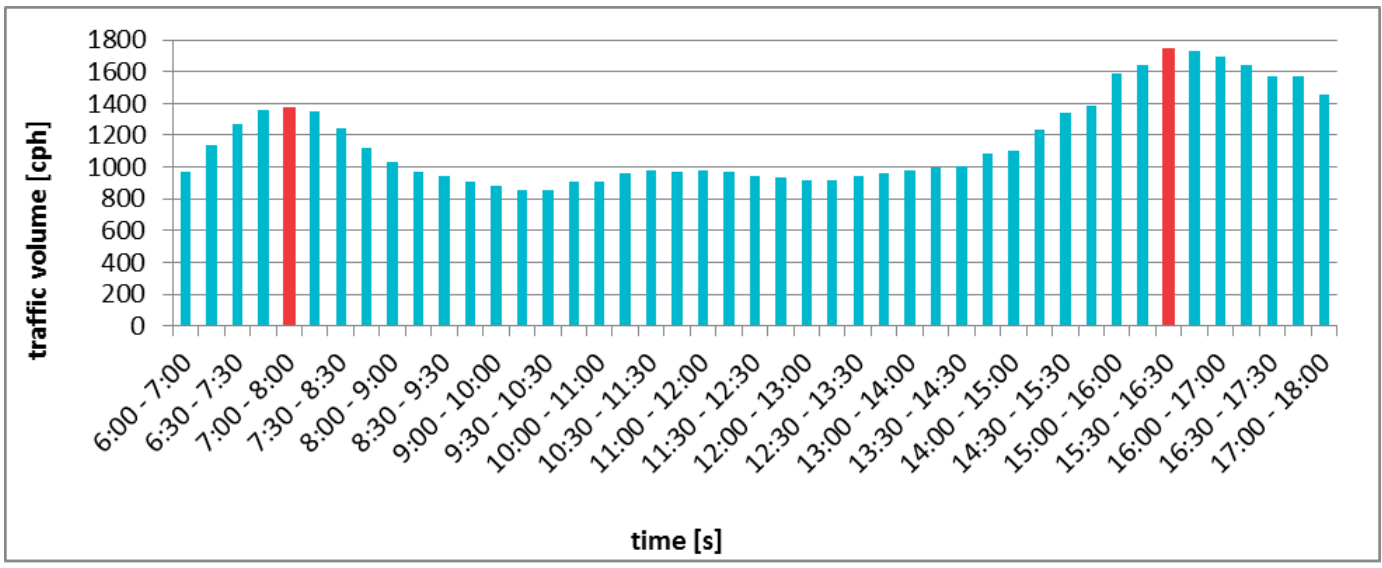

Figure 2 Traffic volumes during the 12-hour survey and peak hour times

times (e.g., compliance with road traffic rules, signalling or nonsignalling the change of direction of the major-stream vehicles, interruptions by pedestrians, deliberate release of minor-stream vehicles by major-stream vehicles) were monitored.

The video recordings were semi-automatically processed using a special software designed for these purposes. All the necessary data about each minor- and major-stream vehicle were recorded into a database. Each minor-stream vehicle with vehicle type, direction and time of arrival and departure at a specific intersection point was recorded. Each major-stream vehicle, using vehicle type, direction and time of passing a certain cross- line in the intersection, was recorded. These raw data were then used for specifying the major stream gaps for each minor-stream vehicle using a specific tool designed for these purposes. Only gaps between the relevant conflicting-stream vehicles of higher priority according to traffic rules (see Table 1) and only minorstream vehicles with at least one rejected lag or gap were taken into account. The result was a list of just one accepted and one or more rejected gaps/lags for each minor-stream vehicle together with its waiting time at the first position. An example of these data is presented in Table 2 . 


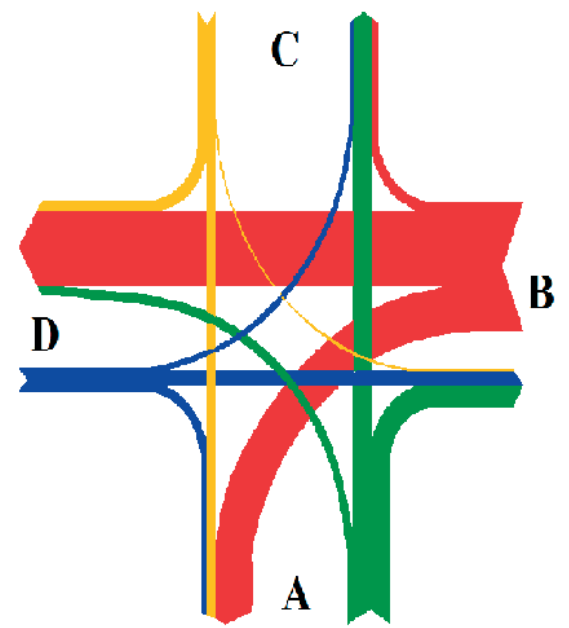

(a)

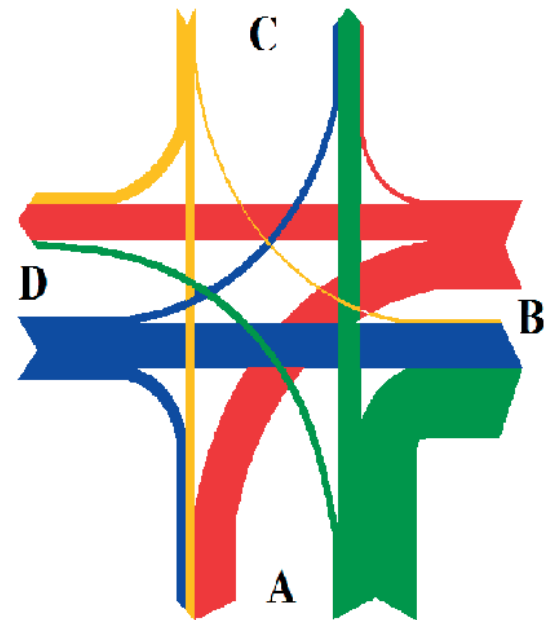

(b)

Figure 3 Pattern of the traffic load redistribution during the morning (a) and afternoon (b) peak hour

Table 2 Example of gap-acceptance data at the investigated intersection

\begin{tabular}{|c|c|c|c|c|c|c|c|c|c|}
\hline \multicolumn{5}{|c|}{ Minor-stream vehicles } & \multicolumn{5}{|c|}{ Major-stream vehicles } \\
\hline $\begin{array}{l}\text { Traffic } \\
\text { stream }\end{array}$ & $\begin{array}{c}\text { Arrival } \\
\text { time }\end{array}$ & $\begin{array}{c}\text { Depart. } \\
\text { time }\end{array}$ & $\begin{array}{l}\text { Veh. } \\
\text { type }\end{array}$ & Waiting time & $\begin{array}{c}\text { Passing } \\
\text { time }\end{array}$ & $\begin{array}{l}\text { Traffic } \\
\text { stream }\end{array}$ & $\begin{array}{l}\text { Veh. } \\
\text { type }\end{array}$ & Gap/lag time & Type \\
\hline \multirow[t]{3}{*}{2} & 819.20 & 826.08 & Car & 6.88 & 820.72 & 4 & $\mathrm{Car}$ & 1.52 & Rejected lag* \\
\hline & & & & & 823.48 & 4 & Car & 2.76 & Rejected gap \\
\hline & & & & & 837.76 & 5 & Car & 14.28 & Accepted gap \\
\hline \multirow[t]{2}{*}{2} & 834.48 & 838.36 & Car & 3.88 & 837.76 & 5 & Car & 3.28 & Rejected lag* \\
\hline & & & & & 846.96 & 5 & Car & 9.20 & Accepted gap \\
\hline \multirow[t]{4}{*}{11} & 847.2 & 860.72 & Car & 13.52 & 851.28 & 1 & Car & 4.08 & Rejected lag* \\
\hline & & & & & 857.92 & 4 & Car & 6.64 & Rejected gap \\
\hline & & & & & 859.52 & 4 & Car & 1.60 & Rejected gap \\
\hline & & & & & 871.12 & 1 & Car & 11.60 & Accepted gap \\
\hline
\end{tabular}

*lag - the time difference between the arrival time of the minor-stream vehicle and passing time of the first conflicting stream vehicle

\section{Estimation of critical gaps}

\subsection{Critical gap}

The critical gap can be defined as the minimum time interval between the major-stream vehicles that is necessary for one minor-stream vehicle to make a maneuver. Values of the critical gaps are different for different drivers and they are dependent on the type of movement, geometry parameters of an intersection and the traffic situation, among others. Due to this variability, the gap acceptance process is considered as a stochastic process and the critical gaps are random variables. Since it is not possible to measure the critical gap time directly, the accepted gap and corresponding largest rejected gap/rejected lag, for each minor-stream vehicle, were used. That means, the data linked to drivers who rejected at least one gap or lag only, were taken into account. Those data were then sorted based on consistent driver behaviour. To obtain the representative sample, the pairs of gaps where drivers had accepted smaller gap than they had rejected, were discarded. Besides that, the other pairs were excluded as well, when accepted or rejected gap had been influenced by other factors such as violation of priority rules or traffic flow interruption by a pedestrian.

The processed and sorted data were used to estimate the critical gaps for three through movements from major and minor street of different priority ranks, highlighted in Table 1 . There is a major-street through movement of Rank 2 (traffic stream 2), a minor-street through movement of Rank 3 (traffic stream 11) and a minor-street through movement of Rank 4 (traffic stream 8). The critical gaps were estimated based on two samples - Sample 1 and Sample 2. Sample 1 consists of pairs of the largest rejected gap and its corresponding accepted gap for each minor-stream vehicle. Sample 2 consists of pairs from Sample 1 supplemented by pairs of accepted gap that has only one pertaining rejected lag. Sample 1 for major-street through movement of the traffic stream 2 is shown in Figure 4.

Several methods for the critical gap estimation are presented in literature [3], [4], [5], [6]. In this paper, three methods were used - the Raff's Method [7], the Troutbeck's Maximum Likelihood Method [8], and Wu's Method [9], which are briefly described below. 


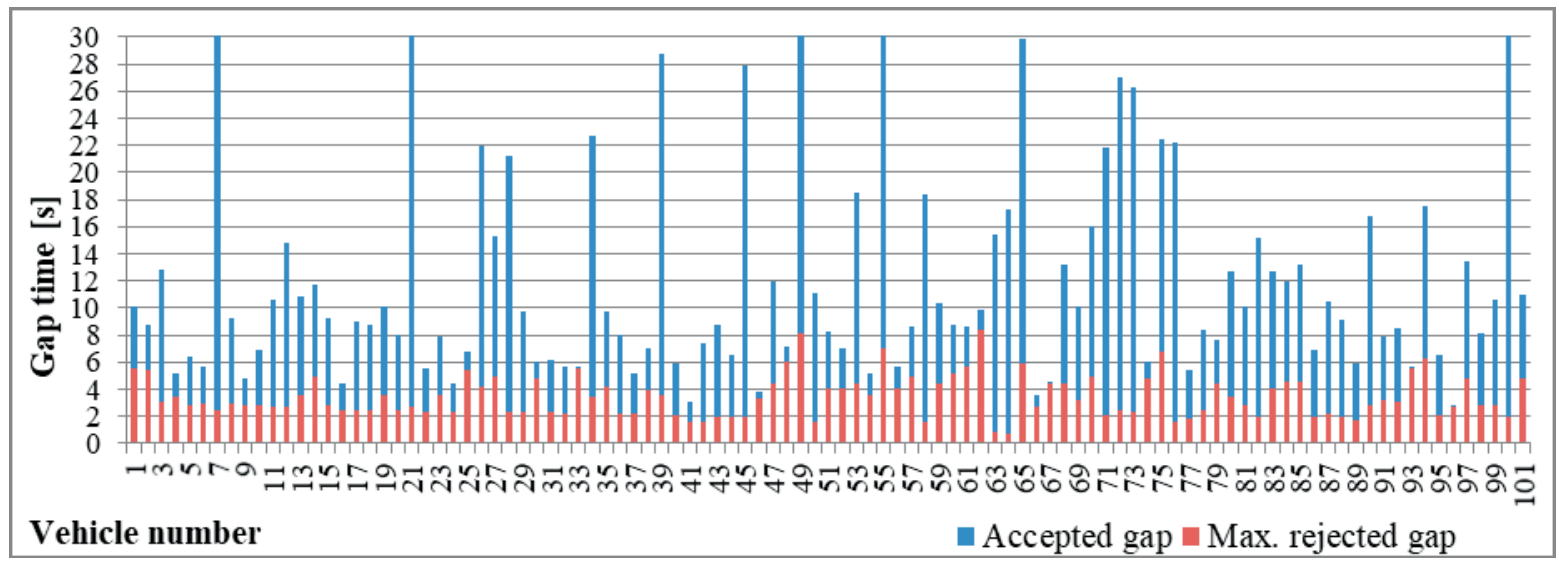

Figure 4 Maximum rejected and accepted gap times for the traffic stream 2 (Sample 1)

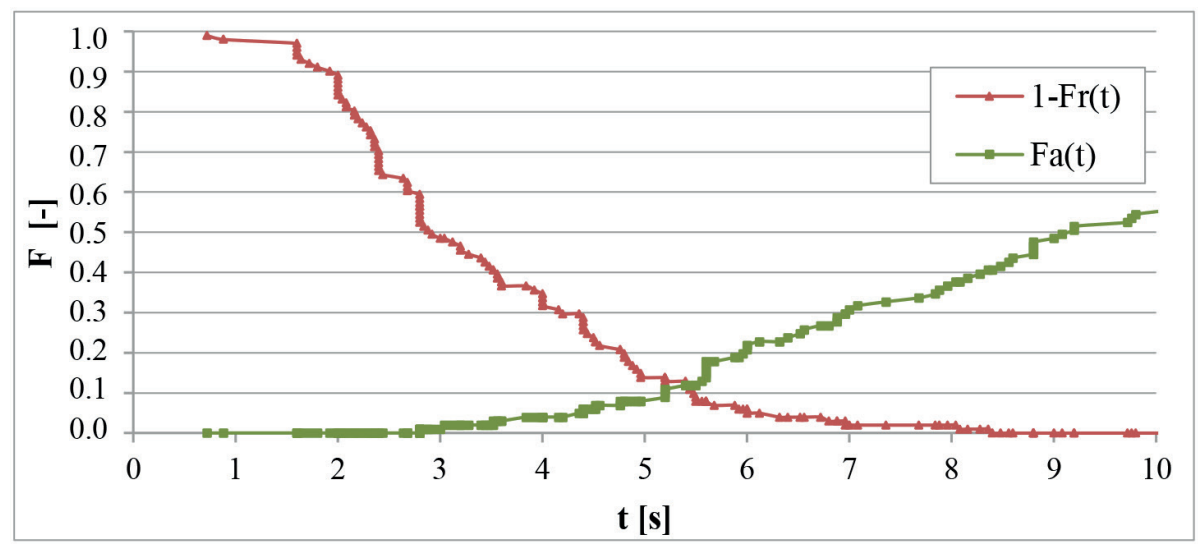

Figure 5 Example of the critical gap estimation according to Raff's method for traffic stream 2

\subsection{Raff's method}

The method of Raff [9], is based on macroscopic model and it is the earliest method for estimating the critical gap which is used in many countries because of its simplicity [4]. This method involves the empirical cumulative frequency distributions of accepted gaps $F_{a}(t)$ and rejected gaps $F_{r}(t)$. When the sum of cumulative curves of accepted gaps and rejected gaps is equal to 1 then a gap of length $t$ is equal to the critical gap $t_{c}$. It means that the number of rejected gaps larger than the critical gap is equal to the number of accepted gaps smaller than critical gap. According to Raff's method, it is the median value of the critical gap [9].

$$
F_{a}(t)=1-F_{r}(t)
$$

Estimation of the critical gap according to Raff's method for traffic stream 2 is shown in Figure 5. Value of the critical gap is in the cross point of cumulative frequency distribution curves $F_{a}(t)$ and $1-F_{r}(t)$.

\subsection{Troutbeck's MLM method}

The model of Troutbeck [8], for the critical gap estimation is based on the Maximum Likelihood Method (MLM) and according to [4] it gives the best results. This microscopic model assumes the log-normal distribution of accepted gaps $\left(a_{i}\right)$ and the corresponding maximum rejected gaps $\left(r_{i}\right)$ for each minor-stream vehicle. The likelihood function is defined as the probability that the critical gap distribution lies between observed distribution of the maximum rejected gaps and the accepted gaps:

$L^{*}=\prod_{i=1}^{n}\left[F\left(a_{i}\right)-F\left(r_{i}\right)\right]$

where:

$L \quad$ - maximum likelihood function,

$a_{i} \quad$ - the logarithm of the accepted gap of vehicle $i$,

$r_{i} \quad-$ the logarithm of the maximum rejected gap of vehicle $i$,

$F\left(a_{i}\right), F\left(r_{i}\right)$ - cumulative distribution functions for the normal distribution.

The logarithm of function (2) is then:

$L=\sum_{i=1}^{n} \ln \left[F\left(a_{i}\right)-F\left(r_{i}\right)\right]$

The parameters of the critical gap distribution function, the mean $\mu$ and variance $\sigma^{2}$, are obtained by maximizing this function. They can be calculated iteratively using the numerical methods. Subsequently, the mean critical gap $t_{c}$ and the variance $s^{2}$ can be computed by equations [8]: 


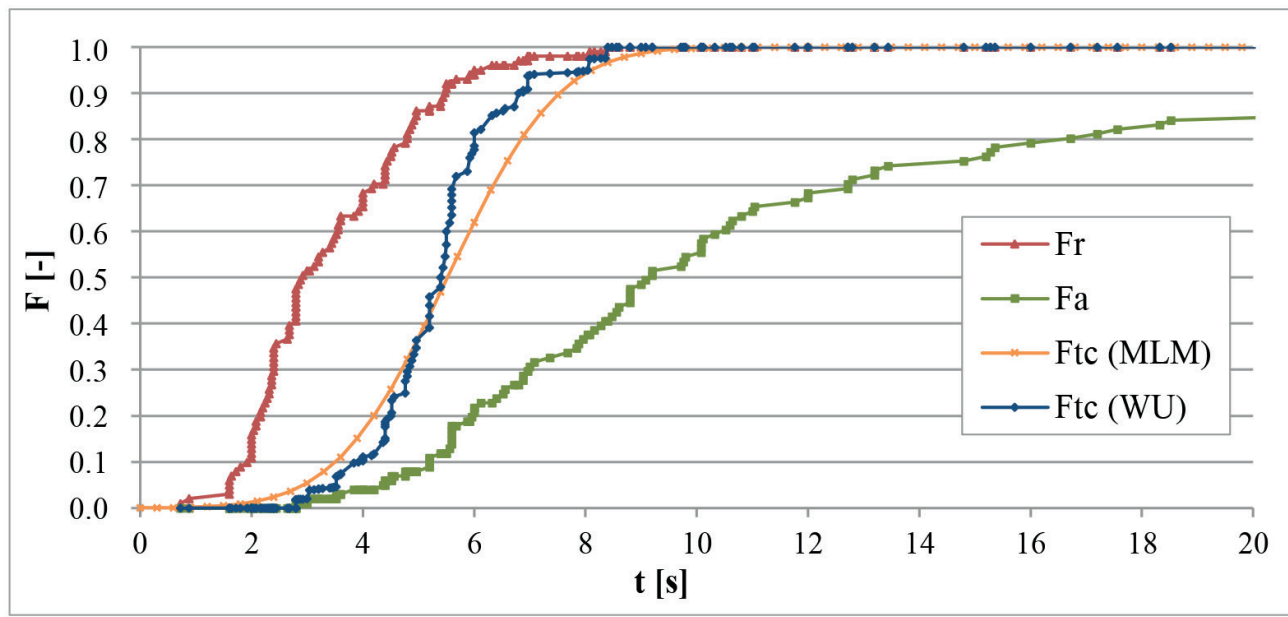

Figure 6 Distribution functions of the maximum rejected gaps (Fr), accepted gaps (Fa), critical gaps from MLM of Troutbeck (Ftc, MLM) and Wu's model (Ftc, WU) for the traffic stream 2

$t_{c}=e^{\mu+0.5 \cdot \sigma^{2}}$

and

$s^{2}=t_{c}^{2} \cdot\left(e^{\sigma^{2}}-1\right)$

respectively.

Distribution functions of the maximum rejected gaps $F_{r}(t)$ accepted gaps $F_{g}(t)$ and the estimated critical gaps by Troutbeck's MLM $F_{t c}(t)$, for the traffic stream number 2, are shown in Figure 6 . The likelihood parameters $\left(\mu\right.$ and $\left.\sigma^{2}\right)$ were obtained by the iteration process programmed in MS Excel. The values of mean of the critical gap $t$ and variance $s^{2}$ were calculated according to Equations (4) and (5).

\subsection{Wu's method}

The Wu's method is quite a recent model for critical gap estimation based on macroscopic probability equilibrium between rejected and accepted gaps [9]. The equilibrium is established macroscopically from the cumulative distribution of the accepted and rejected gaps $F_{a}(t)$ and $F_{r}(t)$. This method, unlike Troutbeck's MLM method, does not require a distribution type of critical gaps and the calculation process is simple without the need of an iteration process. It can be easily implemented into the Excel spreadsheet (detailed calculation procedure step by step is given in [9]). Distribution function of the critical gaps $F_{t c}(t)$ according to $\mathrm{Wu}$ 's model is as follows:

$F_{t c}(t)=\frac{F_{a}(t)}{F_{a}(t)+1-F r(t)}=1-\frac{1-F_{r}(t)}{F_{a}(t)+1-F_{r}(t)}$

For comparison, the distribution function of the critical gaps $F_{t c}(t)$ for the traffic stream 2 calculated in accordance with the $\mathrm{Wu}$ 's model by Equation (6) is drawn in Figure 6.

\section{Results and discussion}

In the following Table 3 are listed the critical gaps of the investigated intersection with bending right-of-way for all the three through traffic streams $(2,11$ and 8$)$, estimated by three methods (Raff, Wu and Troutbeck's MLM) from two samples (Sample 1 and Sample 2). The estimated values of the critical gaps from Sample 1 are higher than the values from Sample 2 with the biggest difference in traffic stream 11 estimated by MLM, where the value of the critical gap decreased by $0.6 \mathrm{~s}$. The comparison of used methods shows small differences for each individual traffic stream. The last two columns in Table 3 show variances of the maximum and minimum values of the critical gaps presented in seconds and percentage. Those differences vary within the range of $3-5 \%$. The Troutbeck's MLM method gives the highest values.

The critical gap value of each individual traffic stream rises with higher priority rank. For the better visual comparison, they are presented in Figure 7. Values of the critical gaps for the traffic stream 2 (major-street through movement of Rank 2) are the smallest (5.0-5.5 $s$ ). They are about 1.3-2 s smaller in comparison to the values of traffic streams 11 and 8 (minor-street through movements of Rank 3 and 4). This is due to the traffic stream 2 being the major traffic stream with higher priority with easier traffic situation for its maneuver. Those values also correspond to the critical gap values listed in the current Slovak regulations TP 102 for similar movement - major-street left-turn movement of Rank 2 for conventional rural four-leg unsignalized intersections [1]. A similar situation is with traffic stream 11 (minor-street through movement of Rank 3), where the critical gap values are between 6.2-7.0 s, depending on the type of sample and estimated method. However, the situation is different for traffic stream 8 , which is also minor-street through movement, but with the lowest priority. The values of the critical gap for this traffic stream are in range 7.1-7.4 s. Values from the field data differ more significantly from the TP 102 values for corresponding priority rank (minorstreet left-turn movement of Rank 4). The reason could be more complicated traffic situation and limited familiarity of drivers with this type of intersection on the road network. 
Table 3 Critical gaps of through movements of Rank 2, 3, and 4 estimated by three methods compared to values from the Slovak regulations TP 102

\begin{tabular}{|c|c|c|c|c|c|c|c|c|}
\hline \multirow[t]{2}{*}{ Sample } & \multirow{2}{*}{$\begin{array}{l}\text { Traffic } \\
\text { stream }\end{array}$} & \multirow[t]{2}{*}{ Priority rank } & \multirow{2}{*}{$\begin{array}{c}\text { RAFF } \\
{[\mathrm{s}]}\end{array}$} & \multirow{2}{*}{$\begin{array}{l}\text { WU } \\
{[\mathrm{s}]}\end{array}$} & \multirow{2}{*}{$\begin{array}{c}\text { MLM } \\
{[\mathrm{s}]}\end{array}$} & \multirow{2}{*}{$\begin{array}{c}\text { TP } 102 \\
\text { [s] }\end{array}$} & \multicolumn{2}{|c|}{$\begin{array}{c}\text { Variance of } \\
\max \text { - min value }\end{array}$} \\
\hline & & & & & & & [s] & $\%$ \\
\hline \multirow{3}{*}{$\mathrm{S} 1$} & 2 & 2. & 5.40 & 5.35 & 5.52 & $5.5^{* 1}$ & 0.17 & 3.1 \\
\hline & 11 & 3. & 6.72 & 6.78 & 7.05 & $6.5^{* 2}$ & 0.33 & 4.7 \\
\hline & 8 & 4. & 7.16 & 7.19 & 7.44 & $6.6^{* 3}$ & 0.28 & 3.8 \\
\hline \multirow{3}{*}{$\mathrm{S} 2$} & 2 & 2. & 5.20 & 4.96 & 5.17 & $5.5^{* 1}$ & 0.24 & 4.6 \\
\hline & 11 & 3. & 6.26 & 6.22 & 6.45 & $6.5^{* 2}$ & 0.23 & 3.6 \\
\hline & 8 & 4. & 7.10 & 7.16 & 7.26 & $6.6^{* 3}$ & 0.16 & 2.2 \\
\hline
\end{tabular}

${ }^{* 1}$ major-street left-turn movement of Rank 2; ${ }^{* 2}$ minor-street through movement of Rank 3; ${ }^{* 3}$ minor-street left-turn movement of Rank 4

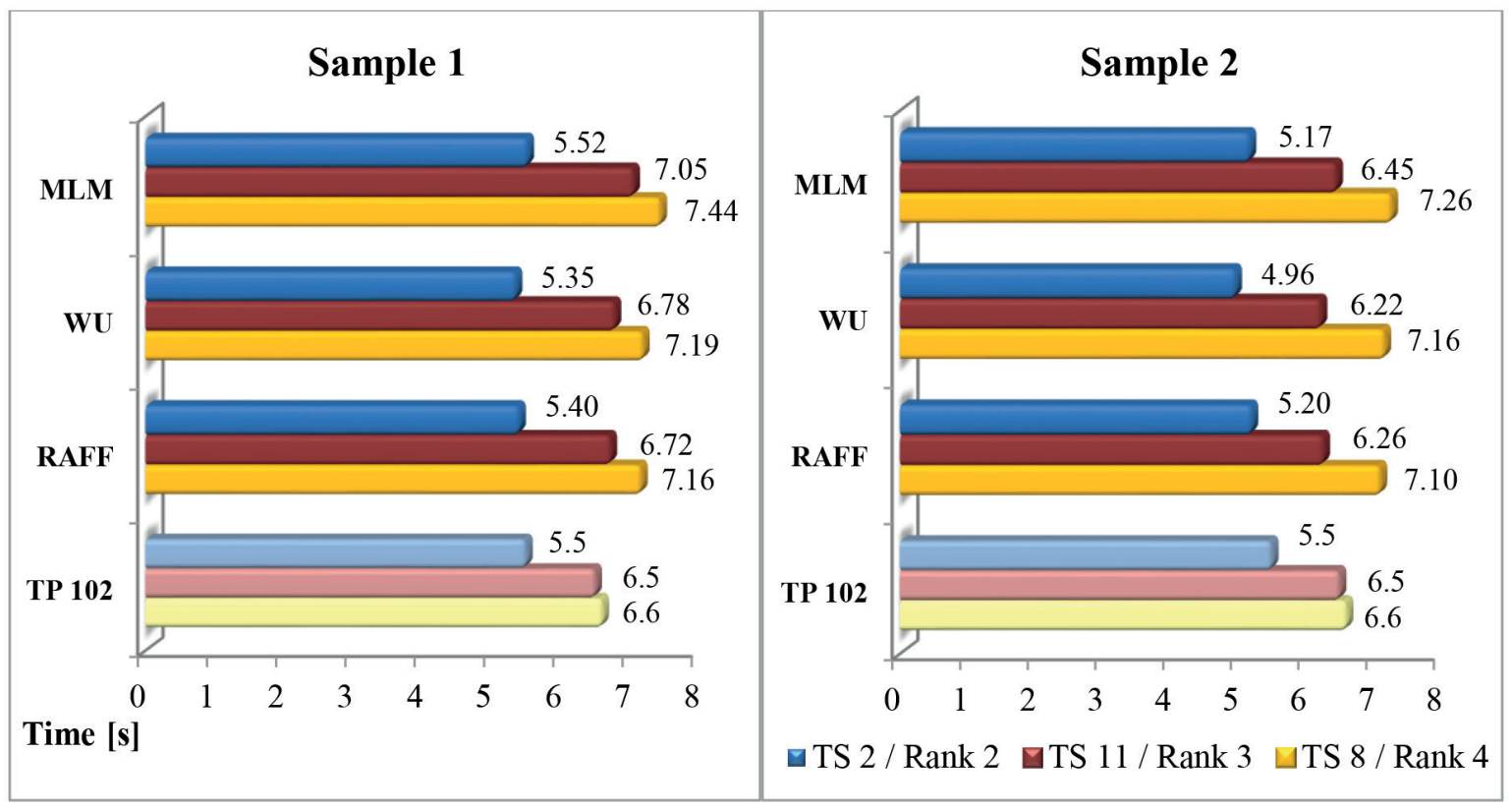

Figure 7 Comparison of the critical gaps of through movements of Rank 2, 3 and 4 estimated by three methods (Raff, Wu and MLM) to TP 102 values

\section{Conclusions}

Different traffic rules of driving at unsignalized intersections with bending right-of-way in comparison to standard intersections result in a different rank of priority of traffic movements. For such specific redistribution of traffic stream ranks, there is no generally applicable procedure for capacity calculation and, so far, only little research has been focused on investigation of the gap acceptance behavior of drivers.

To find out drivers' behavior at this type of intersection, the initial study was focused on investigation of the critical gaps. This paper presents the values of the critical gap times for three through movements of different rank of priority estimated for two samples of entering data by three methods (Raff, Wu and Troutbeck). It points to the following:

The values of the critical gaps, estimated by these three methods, do not differ significantly. These differences vary within the range $3-5 \%$.
The Troutbeck's MLM method gives the highest values, which were about $0.2 \mathrm{~s}$ higher in comparison to Raff or $\mathrm{Wu}$ estimation methods.

Values of the critical gaps depend on the sample of entering data of accepted and rejected gaps. These values are higher for Sample 1, where only pairs of accepted and maximum rejected gaps for each minor-stream vehicle were included in the database. The difference is about $0.2-0.6 \mathrm{~s}$.

The values of critical gaps for the same movements, according to major/minor street and rank of priority, differ more significantly. The values of the critical gaps for the major-street through movement of Rank 2 are the smallest. They are about 1.3-1.5 s smaller in comparison to the values for the same through movement from the minor street of Rank 3 and about 1.8-2.1 s smaller in comparison to Rank 4 . The values of the critical gap for the minor-street through movement of the lowest priority are the highest and they are also higher in comparison to the Slovak regulations TP 102 value for the same priority rank.

The results of the initial study indicate that it is not correct to use the values of the critical gaps valid for unsignalized 
intersections with standard right-of-way in the case of unsignalized intersections with bending right-of-way without verification in practice. This is because the critical gaps for the same traffic movements differ depending on the rank of priority with different traffic situations and therefore, different gap-acceptance behavior of drivers.

While the traffic situation and priority rules are the same for the same movements at a standard four-leg intersection (e.g., minor-street through movements are of the same Rank 3), they are different for each individual inferior traffic stream at the specific four-leg intersection (the same movements are not of the same priority rank). It indicates that values of the critical gaps and the follow-up times should be determined for individual inferior traffic stream separately.

\section{Acknowledgement}

This contribution/publication is the result of the project implementation: Centre of excellence for systems and services of intelligent transport II, ITMS 26220120050 supported by the Research \& Development Operational Programme funded by the ERDF.

\section{References}

[1] TP 102 Roads Capacity Calculation. Technical regulations (in Slovak) [online]. Ministry of Transport, Construction and Regional Development, Bratislava, 2015. Available: http://www.ssc.sk/files/documents/technicke-predpisy/tp2015/tp-16_2015.pdf.

[2] PETRU, J., KRIVDA, V., MAHDAlOVA, I., SKVAIN, V.: Video Analysis of Conflict Situations at T-Intersection with Cranked Priority. Applied Mechanics and Materials, 719-720, 1000-1004, 2015. https://doi.org/10.4028/www.scientific.net/AMM.719720.1000

[3] AMIN, H. J., MAURYA, A. K.: A Review of Critical Gap Estimation Approaches at Uncontrolled Intersection in Case of Heterogeneous Traffic Conditions. The Journal of Transport Literature, 9(3), 5-9, 2015. http://dx.doi.org/10.1590/2238-1031.jtl. v9n3a1

[4] BRILON, W., KONIG, R., TROUTBECK, R.: Useful Estimation Procedures for Critical Gaps. Proceedings of the 3rd International Symposium on Intersections without Traffic Signals, USA, 71-87, 1997.

[5] GUO, R.: Estimating Critical Gap of Roundabouts by Different Methods. Proceedings of the 6th Advanced Forum on Transportation of China, China, 84-89, 2010.

[6] VASCONCElOS, A. L. P, SECO, A. J. M. S, SILVA, A. M. C. B.: Comparison of Procedures to Estimate Critical Headways at Roundabouts. Promet - Traffic\&Transportation, 25(1), 43-53, 2013. https://doi.org/10.7307/ptt.v25i1.1246

[7] RAFF, M. S., HART, J. W.: A Volume Warrant for Urban Stop Signs (cited in [4]). Eno Foundation for Highway Traffic Control, Saugatuck, Connecticut, 1950.

[8] TROUTBECK, R. J.: Estimating the Critical Acceptance Gap from Traffic Movements. Physical Infrastructure Center Research Report 92-5. Queensland University of Technology, Brisbane, Australia, 1992.

[9] WU, N.: A New Model for Estimating Critical Gap and its Distribution at Unsignalized Intersections Based on the Equilibrium of Probabilities. Proceedings of the 5rd International Symposium on Highway Capacity and Quality of Services, Japan, 2006. 